\title{
SEROPREVALENCE OF TRANSFUSION TRANSMISSIBLE INFECTIONS AMONG HEALTHY BLOOD DONORS AT GENERAL HOSPITAL, SONEPAT, NORTH INDIA
}

Rajvir Singh¹, Prakriti Vohra², Pooja Singla³ ${ }^{3}$ Uma Chaudhary4.

1. Demonstrator, Department of Microbiology, PGIMS Rohtak.

2. Assistant Professor, Department of Microbiology, SHKM, GMC, Nalhar, Mewat.

3. Demonstrator, Department of Microbiology, PGIMS Rohtak.

4. Senior Professor, Department of Microbiology, PGIMS Rohtak.

\section{CORRESPONDING AUTHOR}

Dr. Rajvir Singh,

Demonstrator, Dept. of Microbiology,

PGIMS, Rohtak.

Email- rajvirsabharwal@yahoo.in

\section{HOW TO CITE THIS ARTICLE:}

Rajvir Singh, Prakriti Vohra, Pooja Singla, Uma Chaudhary. "Seroprevalence of transfusion transmissible infections among healthy blood donors at general hospital, Sonepat, North India". Journal of Evolution of Medical and Dental Sciences 2013; Vol2, Issue 26, July 1; Page: 4816-4820.

ABSTRACT: - OBJECTIVES: Voluntary donor selection and screening of donor's blood for infective agents are the cornerstones of transfusion medicine. Donor selection is of paramount importance because infected individuals serve as an asymptomatic reservoir and a potential source of transmission to healthy persons. MATERIALS AND METHODS: During the period of five years (01.01.2008 to 31.12.2012), out of a total number of 14026 healthy voluntary donors, there were 13601 males and 425 were females. Age ranged from 18-60 years. Blood was collected in Citrate Phosphate Dextrose Adenine (CPDA-1) bags. STASTICAL ANALYSIS USED: Data was statistically analysed with statistix 9 software. A p value less than 0.05 was considered significant. RESULTS: The seroprevalence of HIV, HBsAg, HCV and syphilis was $0.25 \%, 1.42 \%, 1.10 \%, 0.62 \%$ respectively in total donors. CONCLUSION: This study reflects that blood transfusion is the leading risk factor for spread of the transfusion transmitted infections (TTI), which showed the need and importance of the mandatory screening of these infectious markers in blood donations.

KEYWORDS: Healthy blood donors, Seroprevalence, Transfusion transmissible infections, HIV, Syphilis, HBV, HCV.

INTRODUCTION: Blood transfusion has been used since 1930 for various indications. ${ }^{1}$ Transfusion therapy is a well established treatment in various medical and surgical procedures. ${ }^{2}$ Transfusion medicine, apart from being important for the medical treatment of each patient, also has a great public health importance worldwide. After introduction of blood banks and better storage techniques, it became more widely used. ${ }^{3}$

Blood transfusion also carries the risk of transfusion-transmissible infections like Hepatitis B and C, HIV and Syphilis, malaria and infrequently toxoplasmosis, brucellosis and viral infections like 


\section{ORIGINAL ARTICLE}

CMV, Epstein Barr Virus and Herpes. ${ }^{4}$ Measuring their severity, WHO has recommended pretransfusion blood test for HIV, HBV, HCV and Syphilis as mandatory. All these diseases are capable of causing significant mortality, morbidity along with a financial burden for both the affected person and the country. ${ }^{5}$ Government of India published in the year 2002 the National Blood Policy. The objective of the policy is to provide safe, adequate quantity of blood, blood components and products. Each blood unit shall be tested for presence of HIV 1\&2 antibodies, Hepatitis B surface antigen, and Anti-hepatitis $\mathrm{C}$ virus antibody, syphilis and malaria parasite and results of such testing shall be recorded on the label of the container. With every one unit of blood transfusion there is $1 \%$ chance of transfusion related complications including Transfusion transmitted infections (TTIs). ${ }^{4}$ An increase in Transfusion related infections has been reported in India. ${ }^{6}$ India is already carrying a burden of 50 million HBV carriers and 2.27 million HIV cases. Keeping in mind the grave consequences these infections and to restrain the transmission to minimum, it is very important to remain vigilant about the possible spread of these diseases through blood transfusion. ${ }^{7}$

The objective of this study is to estimate the seroprevalence of transfusion transmitted infections among voluntary blood donors at a rural secondary healthcare facility in North India.

MATERIAL AND METHODS: This study was conducted to evaluate the prevalence of TTIs in healthy blood donors. It was conducted with the approval of Superintendent of the source hospital.

STUDY DESIGN: It was a hospital based retrospective study.

Study location: The data was collected from the blood bank of General hospital, Sonepat samples were tested over a period of five years. The screening of blood for TTIs is mandatory for blood safety in the source hospital.

Study population: 14026 blood donors of both sexes attended the blood bank during this period which was screened for Hepatitis B, Hepatitis C, HIV and syphilis.

Study duration: Records were collected from blood bank of all donors coming to blood bank of General hospital, Sonepat during 1stJanuary 2008 to 31 st December 2012. Name, age (18-60 years), Sex, date of birth, address and contact number were recorded for each donor, while giving them a unique identification number. Detailed history of immunization was taken. A written informed consent was taken from each patient before the blood donation. Weight, pulse, blood pressure and temperature were recorded for each donor. Screening for anemia was done clinically along with copper sulfate specific gravity method. Any donors with previous history of HBV, HCV, HIV and syphilis infections were excluded. Inspection was made for any marks of drug abuse or any skin lesions/ infections at the venepuncture site. Proper sterilization and other precautions were taken during the blood collection and blood units were stored by appropriate methods.

Laboratory tests: Blood sample were collected and tested in the blood bank of General hospital, Sonepat. HBs Ag, anti-HCV, anti-HIV were tested using ELISA (Micro Elisa) kit developed by M/S J. Mitra \& Company Ltd., New Delhi, India, and Venereal Disease Research Laboratory Test (VDRL) for Syphilis was tested using Foresight ${ }^{\circledR}$ Syphilis Total Antibody EIA Test Kit by ACON international according to manufacturer's instructions. 


\section{ORIGINAL ARTICLE}

Statistical analysis: Data was statistically analysed with statistix9 software. A p value less than 0.05 was considered significant.

RESULTS: In the present study, out of 14026 healthy voluntary donors, 13601 were males and 425 were females, showing predominance of males as compared to females, in this study which spanned over a period of five years. (Table 1)

Sixty percent of the donors were in the age group of 21- 30 years. The prevalence of Hepatitis B, Hepatitis C, HIV and Syphilis among voluntary blood donors in the study population is showed in Table 2. The overall seroprevalence of HBV and HCV was $1.42 \%$ and $1.10 \%$ respectively, while the prevalence of Syphilis and HIV as $0.62 \%$ and $0.25 \%$ respectively. The highest prevalence was observed for HBV followed by HCV, syphilis and HIV in decreasing order.

TABLE 1: Sex wise distribution of healthy donors

\begin{tabular}{|l|l|l|l|}
\hline YEAR & TOTAL DONORS & MALES n (\%) & FEMALES n (\%) \\
\hline 2008 & 2009 & $1989(99 \%)$ & $20(1 \%)$ \\
\hline 2009 & 2215 & $2140(96.6 \%)$ & $75(3.4 \%)$ \\
\hline 2010 & 2183 & $2144(98.2 \%)$ & $39(1.8 \%)$ \\
\hline 2011 & 2015 & $1977(98.1 \%)$ & $38(1.9 \%)$ \\
\hline 2012 & 5604 & $5351(95.5 \%)$ & $253(4.5 \%)$ \\
\hline TOTAL & 14026 & $13601(96.9 \%)$ & $425(3.1 \%)$ \\
\hline
\end{tabular}

Table 1.1: Statistical analysis

\begin{tabular}{|l|l|l|l|l|l|}
\hline Source of variation & Sample Size & Difference & M.S. & F ratio & $5 \%$ F limit \\
\hline Between sample & 11322.7 & $(4-1)=3\left(V_{1}\right)$ & 3774.23 & 4.43 & $\mathrm{P}(3,16)=3.24$ \\
\hline Within sample & 13644.46 & $(20-4)=16\left(\mathrm{~V}_{2}\right)$ & 852.77 & & \\
\hline
\end{tabular}

The above table (Table-1.1) shows that the calculated value of $\mathrm{F}$ is 4.43 which is more than tabulated value of 3.24 with difference being $V_{1}=3$ and $V_{2}=16$, hence could have arisen due to chance. We may, therefore, conclude that difference in sex wise distribution of healthy donors is significant and no matter of chance. 
TABLE 2: Seroprevalence of HIV, HBsAg, HCV \& Syphilis among healthy donors

\begin{tabular}{|c|c|c|c|c|c|}
\hline YEAR & $\begin{array}{l}\text { VOLUNTARY } \\
\text { COLLECTION }\end{array}$ & $\begin{array}{l}\text { HIV positive } \\
\text { n (\%) }\end{array}$ & $\begin{array}{l}\text { HBsAg } \\
\text { positive } \\
\text { n (\%) }\end{array}$ & $\begin{array}{l}\text { HCV positive } \\
\text { n (\%) }\end{array}$ & $\begin{array}{l}\text { VDRL positive } \\
\text { n (\%) }\end{array}$ \\
\hline 2008 & 954 & $06(0.63 \%)$ & $18(1.88 \%)$ & $15(1.57 \%)$ & 09 (0.94\%) \\
\hline 2009 & 983 & 07 (0.71\%) & $18(1.83 \%)$ & $09(0.91 \%)$ & $04(0.40 \%)$ \\
\hline 2010 & 1313 & 03 (0.23\%) & $22(1.67 \%)$ & $11(0.83 \%)$ & $02(0.15 \%)$ \\
\hline 2011 & 1433 & NIL (0\%) & $09(0.62 \%)$ & $12(0.83 \%)$ & $04(0.28 \%)$ \\
\hline 2012 & 5120 & $09(0.17 \%)$ & $72(1.40 \%)$ & $61(1.19 \%)$ & $42(0.82 \%)$ \\
\hline TOTAL & 9803 & $25(0.25 \%)$ & $139(1.42 \%)$ & $108(1.10 \%)$ & $61(0.62 \%)$ \\
\hline
\end{tabular}

Total positive cases $=333(3.39 \%)$

TABLE 2.1: Statistical analysis

\begin{tabular}{|l|l|l|l|l|l|}
\hline $\begin{array}{l}\text { Source of } \\
\text { variation }\end{array}$ & Sample Size & Difference & M.S. & F ratio & $5 \%$ F limit \\
\hline $\begin{array}{l}\text { Between } \\
\text { sample }\end{array}$ & 3767.3 & $(4-1)=3$ & 1255.7 & 5.08 & 3.24 \\
\hline Within sample & 3952.25 & $(20-4)=16$ & 247.02 & & \\
\hline
\end{tabular}

The above table shows that the calculated value of $\mathrm{F}$ is 5.08 which is more than tabulated value of 3.24 at $5 \%$ level with difference being $V_{1}=3$ and $V_{2}=16$ and chance could have arisen due to chance. This analysis supports the alternative hypothesis of difference in sample mean. We may therefore, conclude that difference in seroprevalence of HIV, HBsAg, HCV \& Syphilis among healthy donors is significant and no matter of chance. The statistics applied here shows that the difference in rates of seroprevalence of HIV, HBsAg, HCV and Syphilis in healthy donors comes out to be significant. As the value is significant in terms of statistics, so, we can conclude that in Sonepat, in healthy population the prevalence of Hepatitis B is more than Hepatitis C than HIV. However, more studies are warranted in this regard.

DISCUSSION: This study highlights $0.25 \%$ prevalence of HIV infection in healthy donors. Seropositivity of HIV in some other studies was observed to be $0.5 \%, 0.3 \%$, and $0 \% .8,9,10$ Seroprevalence of HBsAg in this study was $1.42 \%$ and in various other studies was $2.9 \%, 1.7 \%$ and $5 \% .8 .9,11$ The occurrence of HBsAg is more than other infectious diseases because of asymptomatic carriers. The prevalence of seropositivity for HCV and Syphilis was $1.10 \%$ and $0.62 \%$ respectively. Indian studies indicate that seroprevalence of HCV ranges between $0.41-09 \% .^{12}$

Majority of the donors (98\%) were male which is comparable to the study done by Rao et al and Arora et al. ${ }^{13,9}$ 


\section{ORIGINAL ARTICLE}

Availability of safe blood for transfusion is a must for the recipients and the community as well. This can be achieved by vigorous screening of donors and donated blood. Effective control strategies including a sensitive and stringent screening of all blood donors, public awareness programs, and institution of adequate public health measures are urgently needed. ${ }^{3}$

CONCLUSION: Blood is still one of main sources of transmission of hepatitis B, hepatitis C, HIV and syphilis. Periodic studies to investigate transfusion-transmissible infectious diseases are required to enable safety reviews of the blood supply.

\section{BIBLIOGRAPHY:}

1. Zafar N. A survey of blood transfusion practices. J coll. Physicians Surg Pak 2000; 10:90-2.

2. Isbister JP. Risk management in transfusion medicine. Transfus Med 1996; 10:183-202.

3. Giri P, Deshpande J, Phalke D, Karle L. Seroprevalence of transfusion transmissible infections in rural India, J Family Medicine \& Health Care, 2012,1: 48-51.

4. Widmann FK, editor. Technical manual American Associations of Blood Banks. Anglington USA: $1985 ; 325-44$.

5. Screening Donated Bloods for Transfusion-Transmissible-Infections, World Health Organization, (http://www.who.int/bloodsafety/ScreeningTTI.pdf).

6. Rose D, Sudarsanam A, Padankatti T, Babu PG, John TJ. Increasing Prevalence of HIV antibody among blood donors monitored over 9 years in blood donors monitored over 9 years in blood banks. Indian J Med Res. 1998; 108: 42-4.

7. Sinha SK, Roychoudhary, Biswas K, Biswas P, Bandopadhyay R. Prevalence of HIV, Hepatitis B, Hepatitis C and Syphilis in donor's blood: A study from eastern part of India, Open Journal of Hematology, 2012, 3-1.

8. Nilima Sawke, Sawke GK, Chawla. Seroprevalence of common transfusion - Transmitted infections among blood donors. People's journal of scientific research 2010; 3(1):5-7.

9. Arora D, Arora B, Khetarpal A. Seroprevalence of HIV, HBV, HCV and syphilis in blood donors in Southern Haryana. Indian J Pathol Microbial 2010; 53(2):308-9.

10. Syed Abdul Mujeeb, Khalid Mehmood. Prevalence of HBV, HCV and HIV infections among family blood donors. Annals of Saudi Medicine 1996;16 (6):702-3.

11. Tulika Chandra, Ashutosh Kumar, Ashish Gupta. Prevalence of transfusion transmitted infections in blood donors: an Indian experience. Tropical Doctor 2009; 39(3):152-4.

12. Ahmed MV, Begum HA, Hossain T, Chakraborty $P$. Incidence of common transfusion transmitted diseases among blood donors. JAFMC Bangladesh 2009; 5(1):4-6.

13. Rao P, Annapurna K, HIV status of blood donors and patients admitted in KEM Hospital Pune. Indian J Hemat Blood Transf 1994;12:174-6. 